\title{
PENGEMBANGAN OSILOSKOP BERBASIS ARDUINO UNO SEBAGAI MEDIA PEMBELAJARAN FISIKA
}

\author{
Hardi Hamzah ${ }^{1, a}$, Kartika Hajati ${ }^{2, b}$, Darmawan ${ }^{3, c}$ \\ 1,2,3 Universitas Sulawesi Barat \\ e-mail; ahardi@unsulbar.ac.id, bjamil_kartika@yahoo.co.id,
}

\begin{abstract}
Abstrak
Tujuan penelitian pengembangan ini adalah untuk menghasilkan produk yang layak digunakan dalam pembelajaran pada materi arus bolak balik. Penelitian ini termasuk penelitian pengembangan yang mengacu pada model pengembangan Borg and Gall. Penelitian ini dilakukan di SMAN 1 Alu Kabupaten Polewali Mandar Provinsi Sulawesi Barat dengan mengujicobakan pada 16 peserta didik yang telah duduk dibangku kelas XII MIPA. Berdasarkan hasil analisis data hasil validasi ahli materi diperoleh persentase skor sebesar $89.88 \%$ kategori sangat layak dan hasil validasi ahli media diperoleh persentase skor sebesar 92.27\% kategori sangat layak. Hasil respon guru fisika persentase skor sebesar 92.19\% kategori sangat layak dan peserta didik diperoleh persentase skor sebesar 82\% kategori sangat layak. Berdasarkan hasil tersebut maka media pembelajaran osiloskop berbasis Arduino uno yang telah dikembangkan sangat layak digunakan sebagai media pembelajaran dan sebagai sarana belajar mandiri peserta didik pada materi arus bolak balik.
\end{abstract}

Kata kunci: Pengembangan Osiloskop, Arus Bolak Balik, Arduino Uno.

\section{DEVELOPMENT OF OSCILLOSCOPE BASED ARDUINO UNO AS A PHYSICS LEARNING MEDIA}

\begin{abstract}
The purpose of this development research is to produce a product that is suitable for use in learning on alternating current material. This research includes development research that refers to the Borg and Gall development model. This research was conducted at SMAN 1 Alu, Polewali Mandar Regency, West Sulawesi Province by testing it on 16 students who were sitting in class XII MIPA. Based on the results of the analysis of the results of the validation of the material experts, the percentage score of $89.88 \%$ in the very feasible category and the results of the validation by the media experts obtained the percentage score of $92.27 \%$ in the very feasible category. The results of the physics teacher's response percentage score of $92.19 \%$ in the very feasible category and students obtained a percentage score of $82 \%$ in the very feasible category. Based on these results, the Arduino Uno-based oscilloscope learning media that has been developed is very suitable to be used as a learning medium and as a means of independent learning for students on alternating current material.
\end{abstract}

Keywords: Oscilloscope Development, Alternating Current, Arduino Uno.

\section{PENDAHULUAN}

Zaman modern sekarang ini perkembangan teknologi dibidang elektronika, khususnya dalam bidang mikrokontroler berkembang begitu pesat, salah satu diantaranya adalah mikrokontroler bersifat open-source yang dikenal dengan nama Arduino. Arduino menyediakan berbagai fungsi, antara lain mengkonversi sinyal analog ke digital (analog digital converter), dan berbagai fungsi lainnya. Arduino yang memiliki kemampuan mengubah tegangan analog ke digital menjadi suatu harapan bahwa Arduino dapat difungsikan sebagai osiloskop, dengan PC atau LCD sebagai penampil sinyalnya. Berbagai fenomena kelistrikan di dunia ini mudah diamati bila 
diproyeksikan ke dalam bentuk grafik dengan menggunakan alat ukur berupa osiloskop [1]. Namun, karena harga osiloskop di pasaran khususnya Indonesia masih terbilang mahal, sehingga penggunaannya menjadi terbatas [2]. Seiring bertambah kompleksnya kebutuhan pengukuran, maka keperluan akan analisa, perekaman, dan pengamatan hasil pengukuran menjadi sangat diperlukan dimana hal ini tidak dapat dilakukan oleh osiloskop analog biasa.

Berbagai fenomena kelistrikan di dunia ini mudah diamati bila diproyeksikan ke dalam bentuk grafik dengan menggunakan alat ukur berupa osiloskop [1]. Namun, karena harga osiloskop di pasaran khususnya Indonesia masih terbilang mahal, sehingga penggunaannya menjadi terbatas [2]. Seiring bertambah kompleksnya kebutuhan pengukuran, maka keperluan akan analisa, perekaman, dan pengamatan hasil pengukuran menjadi sangat diperlukan dimana hal ini tidak dapat dilakukan oleh osiloskop analog biasa. Hal lain yang menjadi kendala pada osiloskop adalah berkaitan dengan kemampuannya yang dapat digunakan dan dibawa ke mana saja (portability). Hal ini terjadi diakibatkan karena meningkatnya kebutuhan pengukuran di berbagai tempat tanpa harus terhalangi oleh ukuran fisik, sumber daya, dan penggunaannya [3]. Osiloskop yang juga sebagai alat ukur dalam bidang elektronika yang berfungsi untuk menampilkan bentuk sinyal keluaran dan masukan rangkaian listrik, baik sinyal analog maupun digital sehingga sinyalsinyalnya dapat dilihat, diukur, dihitung dan dianalisis.

Perkembangan teknologi juga ternyata telah berdampak positif pada dunia pendidikan, khususnya dalam menciptakan taktik mengajar yang diminati peserta didik. Oleh karena itu, guru harus memiliki keahlian dalam memanfaatkan fasilitas pembelajaran yang tersedia di sekolah untuk meningkatkan kualitas peserta didik. Fakta konkret yang ditemui khususnya sekolah-sekolah di perkotaan adalah telah dilengkapi dengan fasilitas khususnya laboratorium yang memadai. Nasib berbeda harus dialami oleh sekolah-sekolah di pelosok atau jauh dari pusat perkotaan. Kondisi sarana dan prasarana khususnya laboratorium sebagai penunjang kegiatan pembelajaran masih jauh dari kata memadai. SMAN 1 Alu salah satu contoh nyata dari permasalahan ini. SMAN 1 Alu adalah sekolah menengah yang berada di Kabupaten Polewali Mandar Provinsi Sulawesi Barat dengan SK pendirian KTSP.207/BK/II/2004. Sekolah tersebut adalah sekolah yang masih tergolong kedalam sekolah tertinggal, hal ini ini dapat dilihat dari segi fasilitas jika dibandingkan dengan sekolah lainnya yang juga berada di Kabupaten Polewali Mandar Provinsi Sulawesi Barat.

Fasilitas yang tersedia di sekolah tersebut, terutama pada peralatan praktikum di laboratorium fisika masih belum bisa dikatakan memadai. Kondisi ini membuat guru terkendala dalam menyampaikan materi khususnya pada materi arus bolak balik mata pelajaran fisika. Belajar fisika adalah pemahaman konsep-konsep serta struktur-struktur fenomena dan peristiwa alam yang dapat dipahami melalui eksperimen [4]. Peserta didik akan lebih mudah memahami pelajaran jika memperoleh pengalaman langsung dari kegiatan eksperimen sehingga akan timbul kebermaknaan dalam belajar.

Berdasarkan hasil studi pendahuluan dengan melakukan observasi dan wawancara di SMAN 1 Alu, diperoleh keterangan dari guru fisika bahwa sulitnya menyampaikan materi arus bolak balik karena tidak adanya media pembelajaran, yaitu osiloskop. Pada materi arus bolak balik, guru membutuhkan osiloskop untuk menunjukkan bentuk gelombang sinyal masukan dan keluaran rangkaian pada arus bolak balik. Namun, karena ketiadaan osiloskop di laboratorium maka guru hanya menyampaikan materi tanpa praktikum, atau dengan kata lain pengenalan osiloskop sebagai penampil gelombang sinyal listrik. Akibatnya, ilmu fisika hanya menjadi 
bacaan dan bahan khayalan peserta didik, sehingga peserta didik langsung saja menggunakan rumus-rumus fisika, tanpa mencoba memahami makna dan konsep yang terkandung di dalam soal yang diberikan. Jika fenomena fisis yang dibahas dalam pembelajaran telah dialami peserta didik maka pemahaman peserta didik akan lebih baik [5].

Kelebihan dari osiloskop berbasis Arduino uno yang dikembangkan adalah mudah untuk dibawah ke mana saja. Osiloskop ini juga dilengkapi dengan power supply tersendiri dan tersedia slot yang memunkinkan untuk menggunakan sumber energi dari baterai. Tampilan osiloskop sangat jelas dan dilengkapi dengan keterangan besaran yang terukur.

\section{METODE PENELITIAN}

Jenis penelitian ini adalah reseacrh and development (R\&D) dengan model pengembangan Borg and Gall. Peneliti membatasi langkah-langkah penelitian pengembangan dari sepuluh langkah menjadi tujuh Langkah. Adapun prosedur yang dilakukan peneliti yaitu: 1) Potensi dan Masalah, 2) pengumpulan Data, 3) Desain Produk, 4) Validasi Desain, 5) Revisi Desain, 6) Uji Coba Produk, 7) Revisi Produk. Secara umum prosedur penelitian dan pengembangan dibuat sebagai berikut [7]:

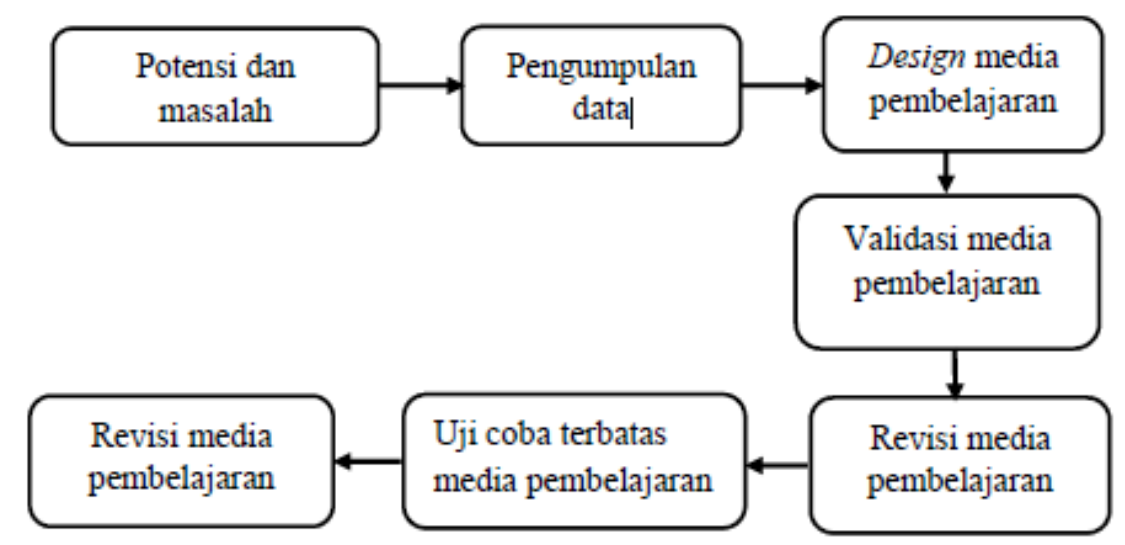

Gambar 1. Bagan alur tahapan penelitian dan pengembangan Osiloskop berbasis Arduino uno

Penelitian ini dilaksanakan di SMAN 1 Alu pada semester ganjil tahun ajaran 2020/2021, pada bulan September. Desain pengujian menggunakan one-shot case study.

\section{$\mathbf{X} \mathbf{O}$}

Keterangan

$\mathbf{X}$ : Treatment yang diberikan

O : Hasil (Respon Peserta Didik)

Setelah memberikan perlakuan menggunakan media pembelajaran osiloskop berbasis Arduino uno, peserta didik kemudian mengisi tabel hasil praktikum kemudian menarik kesimpulan berdasarkan data hasil percobaan. Pada tahap ini juga diberikan lembar angket respon peserta didik. Angket respon peserta didik tersebut bertujuan untuk mengetahui respon peserta didik terhadap media pembelajaran osiloskop berbasis Arduino uno yang telah diujicobakan sebelumnya.

Teknik yang digunakan untuk menganalisis data pada lembar angket dilakukan secara deskriptif kualitatif dan kuantitatif. Data mentah yang telah diperoleh melalui angket ahli materi, ahli media, guru fisika dan peserta didik kemudian ditafsirkan dalam pengertian kuantitatif [7]. Berdasarkan pernyataan di atas maka aturan pemberian skor instrumen 
menggunakan rating scale. Adapun aturan pemberian skor adalah sebagai berikut.

Tabel 1 Aturan Pemberian Skor Butir Instrumen

\begin{tabular}{lll}
\hline Skor & Keterangan & Penilaian \\
\hline 4 & Sangat baik & SB \\
\hline 3 & Baik & B \\
\hline 2 & Kurang baik & KB \\
\hline 1 & Sangat tidak baik & STB \\
\hline
\end{tabular}

Validitas media dilakukan oleh dua ahli yaitu ahli media dan ahli materi dengan aturan pemberian skor menggunakan rating scale. Instrumen yang telah divalidasi kemudian dianalisis dengan menggunakan rumus berikut.

$P_{(k)}=\frac{S}{N} \times 100 \%$

Keterangan :

$P_{(k)} \quad$ : Skor hasil pengukuran data

$S \quad$ : Jumlah skor perolehan

$N \quad$ : Jumlah skor maksimum

Selanjutnya, hasil persentase angket para ahli dan user diinterpretasikan ke dalam tabel klasifikasi tingkat kelayakan produk media pembelajaran osiloskop berbasis Arduino uno, sebagai berikut.
Tabel 2 Klasifikasi Tingkat Kelayakan

\begin{tabular}{llll}
\hline No & $\begin{array}{l}\text { Rerata } \\
\text { skor }\end{array}$ & Persentase & Keterangan \\
\hline 1 & $1,00-$ & $25,0 \%-$ & Sangat tidak \\
& 1,75 & $43,75 \%$ & layak \\
\hline 2 & $>1,76-$ & $44,00 \%-$ & Tidak layak \\
& 2,50 & $62,50 \%$ & \\
\hline No & $\begin{array}{l}\text { Rerata } \\
\text { skor }\end{array}$ & Persentase & Keterangan \\
\hline 3 & $>2,51-$ & $62,75 \%-$ & Layak \\
& 3,25 & $81,25 \%$ & \\
\hline 4 & $>3,26-$ & $81,50 \%-$ & Sangat \\
& 4,00 & $100 \%$ & layak \\
\hline
\end{tabular}

[9]

Pengembangan media pembelajaran osiloskop berbasis Arduino uno pada materi arus bolak balik mata pelajaran fisika layak apabila data hasil uji untuk kerja rerata kelayakan mencapai kriteria minimal "layak" jika ternyata lebih rendah dari kriteria maka media dinyatakan "tidak layak" atau "sangat tidak layak", jika hal itu terjadi maka media pembelajaran tersebut tidak layak atau dapat digunakan dalam pembelajaran.

\section{HASIL DAN DISKUSI Hasil Produk}

Desain media pembelajaran osiloskop berbasis Arduino uno disajikan pada gambar. Desain media terdiri atas tombol on/off, probe osiloskop, LCD, LED, dan power supply untuk mengubah tegangan AC menjadi DC.

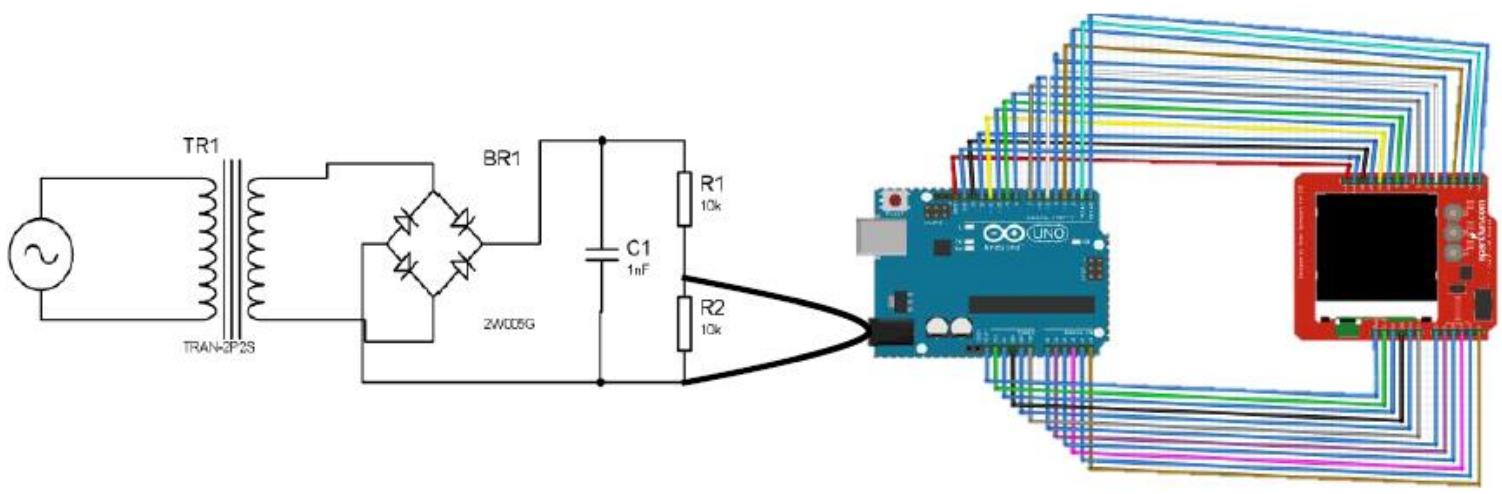

Gambar 1. Hardware Osiloskop Berbasis Arduino uno 


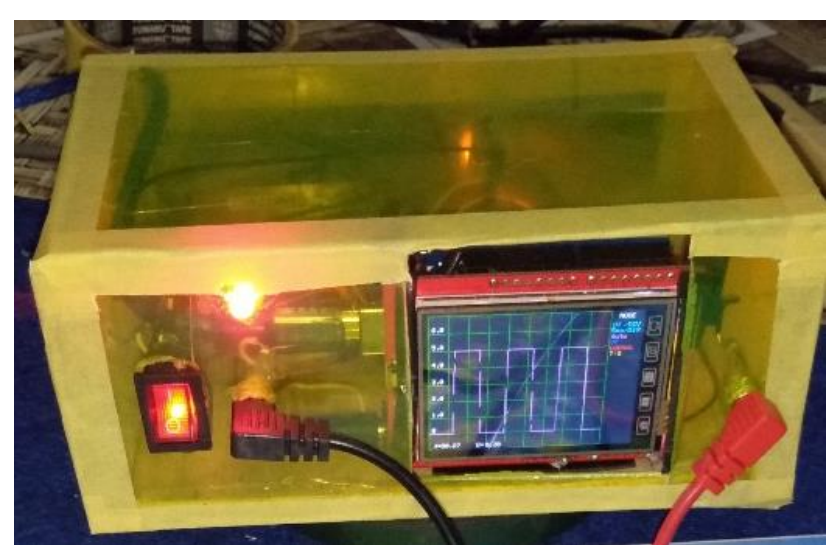

Gambar 2. Tampilan osiloskop berbasis Arduino uno

Tabel 1 Data Validasi Materi

\begin{tabular}{clcc}
\hline No & Aspek Penilaian & Skor & Persentase $(\%)$ \\
\hline \multicolumn{2}{l}{ Media } & & \\
\hline 1 & $\begin{array}{l}\text { Keterkaitan dengan } \\
\text { bahan ajar }\end{array}$ & 6,67 & 83.38 \\
\hline 2 & Nilai pendidikan & 7,67 & 95,88 \\
\hline 3 & Efisiensi alat & 4 & 100 \\
\hline & Buku panduan & & 91,67 \\
\hline 1 & Kelayakan isi & 11 & 83,33 \\
\hline 2 & Kelayakan penyajian & 10 & 91,67 \\
\hline 3 & Kelayakan bahasa & 11 & 90,98 \\
\hline Persentase & & Sangat layak \\
\hline Kategori & &
\end{tabular}

Tabel 2 Data Hasil Validasi Ahli Media Oleh Validator 1

\begin{tabular}{|c|c|c|c|}
\hline No. & Aspek Penilaian & Skor & Persentase $(\%)$ \\
\hline \multicolumn{4}{|c|}{ Media } \\
\hline 1 & Ketahanan alat & 11 & 91,67 \\
\hline 2 & Keakuratan alat & 6,33 & 79,16 \\
\hline 3 & Efisiensi alat & 12 & 100 \\
\hline 4 & Estetika & 3 & 75 \\
\hline 5 & Keamanan & 7,33 & 91,67 \\
\hline 6 & Kotak Kit & 7,33 & 91,67 \\
\hline No. & Aspek Penilaian & Skor & Persentase $(\%)$ \\
\hline \multicolumn{4}{|c|}{ Buku panduan } \\
\hline 1 & Teknis & 16 & 100 \\
\hline 2 & Kelayakan bahasa & 14 & 88 \\
\hline \multicolumn{3}{|c|}{ Persentase } & 89,64 \\
\hline \multicolumn{3}{|c|}{ Kategori } & Sangat layak \\
\hline
\end{tabular}


Tabel 3. Data Hasil Respon Guru Fisika

\begin{tabular}{llcc}
\hline No. & \multicolumn{1}{c}{ Aspek Penilaian } & Skor & $\begin{array}{c}\text { Persentase } \\
(\%)\end{array}$ \\
\hline \multicolumn{3}{l}{ Media } & \\
\hline 1 & Keterkaitan dengan bahan ajar & 7 & 88 \\
\hline 2 & Pendidikan & 4 & 100 \\
\hline 3 & Ketahanan alat & 12 & 100 \\
\hline 4 & Keakuratan alat & 7 & 87.5 \\
\hline 5 & Efisiensi alat & 4 & 100 \\
\hline 6 & Keamanan & 7 & 87.5 \\
\hline 7 & Estetika & 3 & 75 \\
\hline 8 & Teknis & 8 & 100 \\
\hline 9 & Kotak kit & 8 & 100 \\
\hline & Buku panduan & & \\
\hline 1 & Kelayakan isi & 10 & 83.33 \\
\hline 2 & Kelayakan penyajian & 11 & 91.67 \\
\hline 3 & Kelayakan bahasa & 15 & 93.75 \\
\hline Jumlah & & 1106 \\
\hline Persentase skor & & 92 \\
\hline Kategori & & Sangat layak \\
\hline
\end{tabular}

Tabel 4 Data Hasil Respon Peserta Didik

\begin{tabular}{clcc}
\hline No. & Aspek Penilaian & Skor & $\begin{array}{c}\text { Persentase } \\
(\%)\end{array}$ \\
\hline \multicolumn{2}{l}{ Media } & & \\
\hline 1 & $\begin{array}{l}\text { Kualitas isi dan } \\
\text { tujuan }\end{array}$ & 194 & 76 \\
\hline 2 & Teknis & 208 & 81 \\
\hline$\quad$ Buku panduan & & 85.16 \\
\hline 1 & Kelayakan isi & 109 & 85.94 \\
\hline 2 & $\begin{array}{l}\text { Kelayakan } \\
\text { penyajian }\end{array}$ & 55 & 83.20 \\
\hline 3 & Kelayakan bahasa & 213 & 666 \\
\hline Jumlah & & & 82 \\
\hline Persentase skor & & Sangat layak \\
\hline Kategori & &
\end{tabular}

Setiap komponen tersebut dirangkai dan dipasang pada papan rangkaian atau PCB. Hal ini agar komponen terlihat lebih rapi dan aman. Tampilan osiloskop berbasis Arduino uno secara keseluruhan disajikan pada Gambar 2. Uji coba tersebut dilakukan di laboratorium SMAN 3 Majene dan SMAN 1 Majene. Beberapa hal yang diperhatikan dalam uji coba tersebut, seperti bentuk gelombang dan kesesuaian hasil tampilan gelombang pada inputan generator frekuensi.

\section{Hasil Validasi Ahli}

Validitas produk yang dikembangkan diberikan penilaian kepada tiga validator. Setelah media osiloskop berbasis Arduino uno telah selesai dibuat, maka langkah selanjutnya adalah validasi ahli. Validasi ahli tersebut terdiri atas ahli 
materi dan ahli media, tiap ahli masingmasing terdiri atas tiga orang. Proses validasi tersebut menggunakan angket. Data hasil validasi ahli disajikan sebagai berikut.

\section{Ahli Materi}

Data hasil validasi ahli materi untuk media pembelajaran osiloskop berbasis Arduino uno disajikan pada tabel 1 . Berdasarkan hasil persentase skor rata-rata ketiga validator ahli materi yang dikategorikan pada kriteria tingkat kelayakan, maka media pembelajaran osiloskop berbasis Arduino uno pada materi arus bolak balik kelas XII MIPA berada pada kategori sangat layak digunakan dalam pembelajaran.

\section{Ahli Media}

Data hasil validasi ahli media untuk media pembelajaran osiloskop berbasis Arduino uno disajikan pada tabel 2 . Berdasarkan hasil persentase skor rata-rata ketiga validator ahli media yang dikategorikan pada kriteria tingkat kelayakan, maka media pembelajaran osiloskop berbasis Arduino uno pada materi arus bolak balik kelas XII MIPA berada pada kategori sangat layak digunakan dalam pembelajaran.

\section{Hasil Kepraktisan}

Tahap ini dilakukan terhadap guru fisika kelas XII MIPA 1 di SMAN 1 Alu Kabupaten Polewali Mandar. Jumlah guru yang menjadi user dalam tahap uji coba terbatas ini adalah 1 orang. Data hasil respon guru fisika SMAN 1 Alu terhadap media pembelajaran osiloskop berbasis Arduino uno disajikan pada tabel 3. Data hasil respon guru fisika setelah dilakukan analisis data terdapat nilai minimum yaitu pada aspek penilaian estetika, hal ini karena bentuk kotak kit yang masih belum rapi. Berdasarkan hasil persentase skor respon guru fisika pada kategori sangat layak digunakan dalam pembelajaran. Berdasarkan data terlihat bahwa persentase skor berada pada nilai $92 \%$.

\section{Hasil Keefektifan}

Data hasil respon peserta didik kelas XII MIPA 1 di SMAN 1 Alu terhadap media pembelajaran osiloskop berbasis Arduino uno disajikan pada tabel 4. Desain pengujian yang digunakan adalah one-shot case study. Berdasarkan data pada Tabel 4 terlihat bahwa persentase skor sebesar $82 \%$, dan media yang dikembangkan efektif digunakan dalam pembelajaran pada materi arus bolak balik.

\section{SIMPULAN DAN SARAN Simpulan}

Media pembelajaran osiloskop berbasis Arduino uno memenuhi kriteria layak yaitu valid, praktis, dan efektif digunakan sebagai media pembelajaran pada materi arus bolak-balik.

\section{Saran}

Bagi peneliti selanjutnya, sebaiknya menggunakan LCD yanglebih besar agar tampilan media lebih menarik lagi dan mengujicobakan pada beberapa kelas maupun sekolahan untuk lebih mengetahui efektivitas pembelajaran.

\section{DAFTAR PUSTAKA}

[1] Bachmid, A., Vecky, C. P., \& Wasuwung, J., O. (2017). Osiloskop Portable Digital Berbasis AVR ATmega644. Teknik Elektro, Universitas Sam Ratulangi Manado.

[2] Supriandi, Y., Budiawan, I., \& Ekawati, E. (2015). Perancangan dan implementasi osiloskop digital berbasis soundcard. Seminar nasional instrumentasi, kontrol dan otomasi (Pp 167-17). Bandung, Indonesia, 1011desember 2015.

[3] Abdurraziq, Bachmid, A., Vecky, C. P., \& Wasuwung, J., O. (2017). Osiloskop Portable Digital Berbasis AVR ATmega644. Teknik Elektro, Universitas Sam Ratulangi Manado.

[4] Utari, Y. P., Kurniawan, E. S., Fatmaryanti, S. D., \& Fisika, A. H. P. 
(2014). Pengembangan Media Pembelajaran Fisika Online Prezi dalam Pokok Bahasan Alat Optik pada Siswa Kelas X IPA SMA Negeri 3 Purworejo Tahun Pelajaran 2013 / 2014. 5(2), 45-49.

[5] Wijaya, R. (2016). Pembuatan Media Pembelajaran Animasi Bilingual Dengan Menggunakan Software Macromedia Flash 8 Untuk Bab Fluida SMA Kelas X1 Semester Genap. Scienta, 1(1), 156-172.

[6] Sugiyono. (2017). Metode Penelitian \& Pengembangan Research And Development. ALFABETA.bandung

[7] Sugiyono. (2017). Metode Penelitian Pendidikan Pendekatan Kuantitatif,
Kualitatif, dan R\&D. ALFABETA. Bandung

[8] Permana, H., \& Iswanto, B. H. (2018). Development of Thermal Radiation Experiments Kit Based on Data Logger for Physics Learning Media [Artikel dipresentasikan]. IOPConference Series (PP. 1-7). Jakarta:Iop Publishing

[9] Anwar, M. M, Buditjahjanto, I. G. P. A. (2017). Pengembangan Media Pembelajaran Berbasis Komputer Menggunakan Software Flash Pada Mata Pelajaran Komunikasi Data Jurusan Teknik Elektronika Industri Di SMKN 1 Jetis Mojokerto. 131136. 